\title{
Maternal nutrition and reproduction of daughters in wild house mice (Mus musculus)
}

\author{
D. Meikle ${ }^{1}$ and M. Westberg ${ }^{2}$ \\ ${ }^{1}$ Department of Zoology, Miami University, Oxford, OH 45056, USA; and \\ ${ }^{2}$ Department of Medicine, University of Minnesota, Minneapolis, MN 55455, USA
}

Food deprivation after weaning often has greater effects on the reproductive success of females than of males. However, if animals are deprived prenatally (that is, through food deprivation of the mother during gestation), the reproductive success of males may be more adversely affected than that of females because of a disruption in the organizational effects of testosterone in neonatal male mice. The hypotheses that daughters of female mice deprived of food during gestation would have lower reproductive success than control daughters, but that the impact of maternal food deprivation would be lower for daughters than it would be for sons, was tested. There was no difference in the proportion of daughters of food-deprived and control mothers that produced one or two litters. However, the mean number of pups weaned in the second litters by daughters of control females $(5.9 \pm 0.57$ SEM) was greater than the number of pups weaned by daughters of food-deprived females $(4.5 \pm 0.65 \mathrm{SEM})$. There were no differences in the mean birth or weaning body weights of offspring. Therefore, maternal food deprivation in mice may have a small but significant effect on the reproductive success of daughters. However, studies of sons born to females that were subjected to the same food deprivation protocol indicate that maternal food deprivation may have a much greater effect on the reproduction of sons than on that of daughters.

\section{Introduction}

Female mammals usually have a lower variance than do males in reproductive success (Alexander et al., 1979; Clutton-Brock, 1988; Clutton-Brock and Parker, 1992), in part, because female mammals, unlike males, typically do not compete for access to mates and, therefore, usually have higher survivorship than males (for example, see Clutton-Brock, 1988; Meikle and Vessey, 1988; Paul and Kuester, 1990; Paul et al., 1992). In addition, the probability of female mammals being chosen as mates does not vary as much as that of males (Clutton-Brock et al., 1988; Meikle et al., 1995). This sex-related asymmetry in reproductive success may result, in part, from an asymmetry in the way maternal condition (for example, nutritional state) influences the development and subsequent reproductive success of daughters and sons (Trivers and Willard, 1973; Clutton-Brock, 1988).

Food deprivation of both sexes shortly after weaning appears to have more serious effects on the reproductive success of females than of males (McClure, 1966; Bronson, 1985, 1989; Hamilton and Bronson, 1985). For example, food deprivation that is sufficient to reduce significantly the frequency of litters produced by female mice does not reduce the production or storage of spermatozoa in male mice, although body size of male mice can be affected significantly (Bronson, 1985; Hamilton and Bronson, 1985).

Email:meikled@muohio.edu
However, some evidence indicates that if offspring are deprived of nutrients or calories in utero because the mother is food-restricted, the reproductive success of sons may be more seriously affected than that of daughters (Labov et al., 1986; Meikle et al., 1995; Meikle and Westberg, 2001).

For example, in the house mouse (Mus musculus), sons born to females that are deprived of food during gestation have a lower body weight at weaning and as adults than sons born to well-nourished females (Wright et al., 1988; Meikle and Thornton, 1995). The sons of food-deprived females are also more likely to be lower ranking than the sons of mothers fed ad libitum, and are more likely to have smaller preputial glands and seminal vesicles (Meikle and Westberg, 2001). In addition, oestrous females prefer the odours of sons born to females that are well nourished during gestation to those born to food-deprived females (Meikle et al., 1995). The sons of females that are fed ad libitum are more frequently dominant in agonistic encounters than are sons of food-deprived females (Meikle and Westberg, 2001) and oestrous females prefer the odours of dominant males (Drickamer, 1992). Hence, evidence indicates that if a female mammal is deprived of food during gestation, her sons may be disproportionately represented among males that do not survive to maturity (for example, see Meikle and Vessey, 1988; Wasser and Norton, 1993; Meikle and Westberg, 2001) or among those that survive but have relatively low reproductive success (CluttonBrock, 1988).

There are only limited data about the potential effects of 
the nutritional state of mothers during gestation on daughters. However, some evidence indicates that maternal nutrition does not have as large an impact on the reproductive success of daughters as it does on that of sons. For example, Wright et al. (1988) reported no differences in the birth body weights of daughters born to mothers that were either fed ad libitum, or moderately or seriously deprived of food during gestation. In fact, daughters born to the most seriously food-deprived mothers actually weighed more at weaning than those born to mothers that were either moderately deprived of food or fed ad libitum. Similarly, Meikle and Thornton (1995) reported no differences in the birth or weaning body weights of daughters born to females that were slightly deprived of food during gestation compared with those born to mothers fed ad libitum. Drickamer and Meikle (1988) found that depriving mothers of food during gestation had no effect on the timing of the first oestrus, or the body weights at weaning or sexual maturity of their daughters.

Taken together, this evidence indicates that the potential reproductive success of sons of food-deprived females is significantly lower than that of sons born to females fed ad libitum during gestation. However, there does not appear to be such a large difference in the reproductive success of daughters born to food-deprived and control (fed ad libitum) mothers. It is possible that sons are more seriously affected because maternal food deprivation disrupts the organizational effects of testosterone that occur in neonatal male mice (Breedlove and Arnold, 1980; Lung and Cunha, 1980) and, therefore, has significant adverse effects on their development and reproductive success (Meikle and Westberg, 2001). No such organizational effects are anticipated for female mice (Breedlove and Arnold, 1980; Breedlove, 1992); however, the direct impact of maternal food deprivation during gestation on the reproductive success of daughters has not been examined.

The aim of the present study was to test the hypothesis that in wild house mice, the reproductive success of females born to mothers deprived of food during gestation would be lower than the reproductive success of daughters born to females fed ad libitum. This study is a continuation of earlier studies in which the effects of maternal food deprivation on the development and reproductive potential of sons and daughters were examined (Meikle and Drickamer, 1986; Drickamer and Meikle, 1988; Meikle et al., 1995; Meikle and Thornton, 1995; Meikle and Westberg, 2001). In the present study, a food deprivation protocol was used that in previous studies has been shown to have large effects on male reproductive success, specifically, adult body weight, attractiveness to oestrous females, ability to win agonistic encounters and mass of accessory sex glands (Meikle and Thornton, 1995; Meikle et al., 1995; Meikle and Westberg, 2001). The results of these studies indicate that the reproductive success of sons of food-deprived mothers may be significantly lower than that of sons of control mothers. Hence, the second aim of the present study was to test the hypothesis that any difference in the reproductive success of daughters of food-deprived and control mothers is smaller than the potential difference in the reproductive success of sons of the two types of mother.

Food deprivation of mothers during gestation may reduce the ability of adult daughters to invest in offspring; therefore, it was hypothesized that a smaller proportion of the daughters of food-deprived mothers would produce first or second litters than daughters of control mothers. In addition, it was predicted that there would be fewer pups in litters of daughters of food-deprived mothers at birth and especially at weaning compared with litters born to daughters of control mothers.

\section{Materials and Methods}

House mice (Mus musculus) were obtained from an outbred colony that was established with approximately 80 wild mice captured from five sites in Frederick County, MD. All animals were housed individually after weaning (21-22 days) in opaque polypropylene cages $(15 \mathrm{~cm} \times 28 \mathrm{~cm} \times 15$ $\mathrm{cm}$; Ancare Corp., Bellmore, NY). The colony rooms were maintained at $22^{\circ} \mathrm{C}$ and at $30-70 \%$ relative humidity with a $14 \mathrm{~h}$ light:10 $\mathrm{h}$ dark photoperiod. Water was available ad

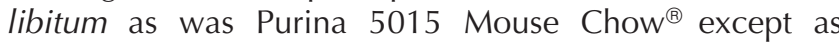
described below. For experimental animals, primiparous females were assigned randomly to either food-deprived ( $n=60)$ or control $(n=48)$ groups. More females were assigned to the deprived treatment group because female mice deprived of food during gestation have lower fertility (Meikle and Thornton, 1995; Meikle and Westberg, 2001).

Female mice in the control and food-deprived groups were paired randomly with adult males (no sibling pairs). At 10 days after pairing, males were removed and females were deprived of food for $24 \mathrm{~h}$ and then for $24 \mathrm{~h}$ on every third day for a subsequent 10 days (food deprivation for a total of 4 days). Food was available ad libitum on the other days and also after birth for all animals. Two cotton nestlets were provided for each female as nesting material. The wild animals used were captured either by hand or in a plastic bag for close inspection. The presence of copulatory plugs was not examined to avoid stressing the females by frequent capture and restraint. The gestation period of wild female house mice is 19-21 days (Rugh, 1968); therefore, it was possible to estimate the day of conception in relation to the timing of food deprivation from the day of birth.

In some food deprivation studies, female mice were fed an invariable and inadequate diet (that is, below the level of consumption that animals choose if fed ad libitum) each day (for example, see Rivers and Crawford, 1974; McClure, 1981; Labov et al., 1986). However, fluctuations in food availability and dominance rank-related access to food may occur daily for species like mice (Jakobson, 1981; Ward, 1981; Bronson, 1985). Hence, in the present study, female mice were deprived of food during gestation on an intermittent (that is, at 3 day intervals) basis. More frequent removal of food during gestation results in very low birth 
rates (Drickamer and Meikle, 1988). Females that are deprived of food for $24 \mathrm{~h}$ every third day during the second half of gestation give birth to litters that are smaller than those of control females (Meikle and Thornton, 1995). In addition, although female mice deprived of food for $24 \mathrm{~h}$ every third day regain much of their lost body weight during the 2 day period of ad libitum feeding, these mice weigh significantly less at parturition than control females (Meikle and Thornton, 1995).

The female offspring of control and food-deprived females were caged individually at 21 days of age. On some occasions, data were collected for more than one daughter from each litter. In those cases, the average scores for the sisters from each litter were calculated and used as single data points for statistical analysis. At all times during the experiments described below, the daughters of control and food-deprived mothers were fed ad libitum. These animals are referred to as 'control daughters' and 'deprived daughters' to highlight the fact that only their mothers were deprived of food during gestation.

When the daughters of control and food-deprived mothers were 90 days old, 30 daughters were selected randomly from each group (all mice were within 1 week of age of each other) for comparison of the reproductive success of individually caged control and deprived daughters. Each control and deprived daughter was weighed and paired with a male chosen randomly. At day 10 after pairing, the male was removed and at day 19 after pairing cages were checked each day for the presence of offspring. On the day each litter was born, the female was weighed, the litter sexed, and all male and female pups were weighed, as they were at 21 days (weaning). The mean body weight for male and female offspring at birth and at weaning was then calculated.

Daughters of food-deprived and control females were paired with a second male about 2 months after the first pairing. Female mice that produced a litter with the first male were able to produce a second litter with the second male. In addition, female mice that did not produce a litter with the first male were able to produce a first litter with the second male, which may have been more attractive to them than the first male (for example, see Drickamer et al., 2000). Data on litters from the second pairing were collected as for those from the first pairing.

\section{Statistical analysis}

Levene's test (SPSS Inc., 1996) was used to determine whether variances were homogeneous. As it was not possible to correct for unequal variances in the secondary (at birth) sex ratio data by any transformations, the sex ratio results were analysed using non-parametric statistics (Siegel, 1956). For all tests for which we had predictions, one-tailed probabilities are reported. Two-tailed probabilities were used for all other tests and all means are \pm SEM. The number of litters for which the mean birth body weights or mean weaning body weights are available, are lower than the number of litters born because some pups were partially consumed at birth and in a few litters some or all pups died before weaning. Power analyses (Howell, 1982) for all comparisons of the number of pups born and weaned by daughters of food-deprived and control mothers were also performed.

\section{Results}

Food-deprived mothers produced litters 20-24 days after pairing with a male. Hence, conceptions occurred approximately 6-10 days before the food deprivation treatment began. Control mothers produced litters 20-26 days after pairing. The greater the time it took for fooddeprived mothers to give birth to a litter (that is, the closer that food deprivation occurred with respect to conception) the smaller the size of the litter $\left(R^{2}=0.93, F_{1,3}=38.25\right.$, $P<0.025)$, indicating that food deprivation caused resorbtion of some embryos.

Among the adult daughters of food-deprived and control mothers, there was no difference in the proportion of females that gave birth after being paired with one male (control: 19 of $30=0.63$; deprived: 16 of $30=0.53$; $\left.\chi^{2}=0.62, \mathrm{df}=1, P>0.1\right)$. The proportion of daughters of food-deprived and control mothers that did not produce a litter after pairing with the first male did not differ when daughters were paired with a second male (total producing at least one litter: 24 of $30=0.80 \%$ of daughters of control mothers and 22 of $30=0.73 \%$ of daughters of fooddeprived mothers; $\chi^{2}=0.12, \mathrm{df}=1, P>0.1$ ). In addition, all 19 daughters of control mothers and 16 daughters of food-deprived mothers that had a litter after the first pairing also had a litter after the second pairing.

The mean number of pups born in the first litters did not differ between control and deprived daughters $(t=0.88$; $\mathrm{df}=44 ; P>0.1$ ) (Fig. 1). However, the mean number of pups born in the second litters was higher for controls than for daughters of food-deprived mothers $(t=1.75, \mathrm{df}=33$, $P=0.05$; Fig. 1). For first and second litters combined, there was no difference in the mean number of pups born to daughters of control and food-deprived females $(t=0.49$; $\mathrm{df}=44 ; P>0.1$; Fig. 1). As the difference between the mean numbers of total pups born in both litters was relatively small $(0.6 \pm 0.83$ pups per litter), the power of the analysis was low ( $\delta$ approximately 0.10 ).

There were also no differences in the mean numbers of pups weaned in the first litters $(t=0.62 ; \mathrm{df}=41 ; P>0.1)$. The number of pups weaned by control females in the second litters was greater than the number of pups weaned by daughters of food-deprived females $(t=1.72 ; \mathrm{df}=27$; $P=0.05$, Fig. 2). In addition, for first and second litters combined, the mean number of pups weaned for control and food-deprived daughters did not differ $(t=0.45$; $\mathrm{df}=35 ; P>0.1 ;$ Fig. 2). Again, because the differences in the mean numbers of total pups weaned from both litters was so small $(0.6 \pm 0.93$ pups per litter), the power of the analysis was relatively low ( $\delta$ approximately 0.10 ). 


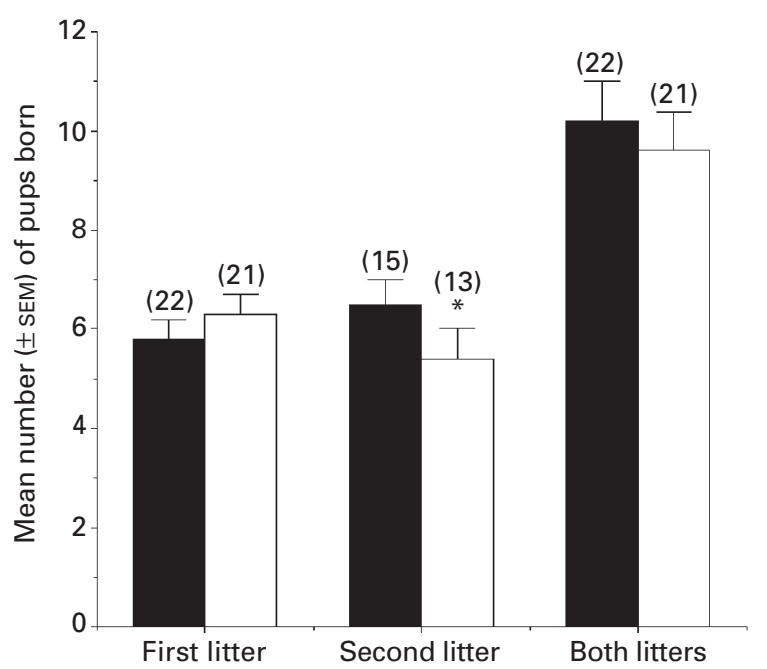

Fig. 1. Mean number ( \pm SEM) of pups born to daughters of control (ם) and food-deprived ( $\square$ ) females in first and second litters, and in both litters combined for the wild house mouse Mus musculus. Number of litters shown in parentheses. *Significantly different from control group of second litter $(P<0.05)$.

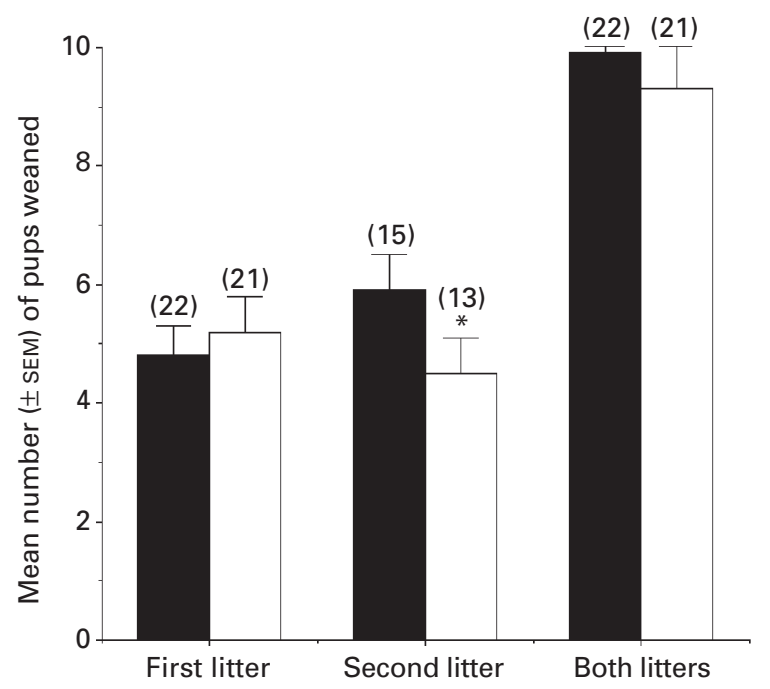

Fig. 2. Mean number $( \pm$ SEM) of pups weaned by daughters of control ( $\square$ ) and food-deprived $(\square)$ females in first and second litters, and in both litters combined for the wild house mouse Mus musculus. Number of litters shown in parentheses. *Significantly different from control group of second litter $(P<0.05)$.

The mean body weights at first mating of the daughters of control and food-deprived females did not differ $(t=0.08$; $\mathrm{df}=58 ; P>0.1)$ or at first parturition $(t=0.06 ; \mathrm{df}=44$; $P>0.1$; Table 1$)$. The body weights of females at mating and at parturition for their second litters did not differ $(t=1.2 ; \quad \mathrm{df}=33 ; P>0.1$ and $t=0.4 ; \quad \mathrm{df}=33 ; P>0.1$, respectively; Table 1 ). There were also no differences between the daughters of control and deprived females in the mean body weights of their male or female offspring at birth $(t=0.9$ and 0.4 , respectively; $P>0.1)$ or at weaning $(t=0.7$ and 0.6 , respectively; $P>0.1)$ for first litters (Table 1 ), or at birth (both $t<0.26 ; P>0.1$ ) or at weaning (both $t<0.4 ; P>0.1$ ) for second births (Table 1 ).

For daughters of control and deprived females, the mean body weights of males and females at birth and at weaning were regressed on litter size to determine whether there was any evidence of trade-off between litter size and the mean body weights of the pups (for example see, Krackow, 1997). The number of pups born to control females was not associated with the mean birth $\left(R^{2}<0.03 ; F<0.2 ; P>0.5\right.$, respectively) or weaning body weights $\left(R^{2}<0.04 ; F<0.25\right.$; $P>0.5$, respectively) of male or female pups. However, the more pups born to food-deprived mothers, the lower the mean birth body weights $\left(R^{2}=0.27 ; F_{1,31}=11.3\right.$; $P<0$. 005) and mean weaning body weights of sons $\left(R^{2}=0.29 ; F_{1,27}=10.8 ; P<0.005\right)$. In addition, the more pups born to the daughters of food-deprived females, the lower the weaning body weights $\left(R^{2}=0.20 ; F_{1,27}=10.8\right.$; $P<0$. 015), but not the birth body weights $\left(R^{2}=0.06\right.$; $\left.F_{1,31}=2.0 ; P>0.1\right)$, of their daughters.

Daughters of control females gave birth to a greater proportion of sons (0.58) in their first litters than did the daughters of food-deprived females (0.44; Mann-Whitney $U$ test $=141 ; \quad P<0.05)$, although the proportions at weaning did not differ $(U=112 ; P>0.05)$. In second litters, there was a trend towards control daughters giving birth to more sons $(U=53 ; P=0.075)$, although at weaning this trend was weaker $(U=48.5 ; P>0.1)$.

\section{Discussion}

The results of the present study indicate that daughters of food-deprived mothers have slightly lower reproductive success than do daughters of control mothers. If these results are representative of reproduction of wild mice in nature, daughters of mothers fed ad libitum wean on average about one more pup from their first two litters compared with daughters of food-deprived mothers. In addition, the difference in the number of pups weaned may increase in third and subsequent litters. However, estimates of survivorship among females in populations of wild mice (Singleton, 1989; Singleton and Redhead, 1990; Triggs, 1991) indicate that the average female in the wild probably does not produce more than (or even as many as) two litters.

Studies on long-lived species, such as humans, indicate that maternal food deprivation may increase rates of disease (for example, cardiovascular disease) among adult postreproductive offspring (for an example see, Barker, 1999). However, because house mice have relatively short lifespans (Singleton, 1989; Singleton and Redhead, 1990; Triggs, 1991), it seems unlikely that such disease-related differences in survivorship among control and deprived daughters would have a strong impact on their lifetime reproductive success. In addition, on the basis of other measurements, there is no strong evidence to indicate that 
Table 1. Mean body weights ( \pm SEM) of control and deprived daughters at mating and birth, and of pups for each litter at birth and weaning for first and second litters in the wild house mouse, Mus musculus

\begin{tabular}{lllll}
\hline & Control mice & $n$ & Deprived mice & $n$ \\
\hline First Litter* & & & & \\
Daughters & & & & \\
$\quad$ Maternal weight (g) at mating & $16.9(0.5)$ & 30 & $16.8(0.5)$ & 30 \\
$\quad$ Maternal weight (g) at birth & $19.8(0.5)$ & 24 & $19.8(0.5)$ & 22 \\
Pups & & & & \\
$\quad$ Weight (g) of male pups at birth & $1.3(0.04)$ & 21 & $1.3(0.4)$ & 20 \\
$\quad$ Weight (g) of male pups at weaning & $9.5(0.3)$ & 19 & $9.2(0.4)$ & 18 \\
Weight (g) of female pups at birth & $1.2(0.05)$ & 20 & $1.3(0.05)$ & 21 \\
$\quad$ Weight (g) of female pups at weaning & $8.8(0.3)$ & 18 & $8.6(0.3)$ & 18 \\
& & & & \\
Second Litter* & & & & \\
Daughters & $19.5(0.7)$ & 19 & $18.5(0.3)$ & 16 \\
$\quad$ Maternal weight (g) at mating & $22.0(0.6)$ & 19 & $21.8(0.5)$ & 16 \\
$\quad$ Maternal weight (g) at birth & & & & \\
Pups & $1.4(0.04)$ & 15 & $1.4(0.06)$ & 12 \\
$\quad$ Weight (g) of male pups at birth & $9.8(0.2)$ & 14 & $10.1(0.4)$ & 11 \\
$\quad$ Weight (g) of male pups at weaning & $1.3(0.04)$ & 15 & $1.7(0.37)$ & 12 \\
$\quad$ Weight (g) of female pups at birth & $9.4(0.2)$ & 14 & $9.1(0.3)$ & 11 \\
$\quad$ Weight (g) of female pups at weaning & & & \\
\hline
\end{tabular}

*No significant differences were found between deprived and control house mice.

Values in parentheses are \pm SEM of body weights.

daughters of food-deprived and control mothers differ in their survivorship. For example, no body weight differences at parturition or at mating were found in the present study between the daughters of control and food-deprived females. Wright et al. (1988) reported that daughters of food-deprived mothers actually weighed more at weaning than daughters of control mothers.

The offspring of daughters of control and food-deprived females did not differ in their mean birth or weaning body weights, although the mean body weights of sons and daughters of food-deprived mothers decreased with increasing litter size. However, there is no clear indication that the offspring of daughters of control and food-deprived females would be at a disadvantage in terms of survival or reproductive success (DeFries and McLearn, 1970; Fuchs, 1981; Krackow, 1993; König, 1994). Finally, the timing of first oestrus in daughters of mothers deprived of food during gestation is not delayed (Drickamer and Meikle, 1988). Although the results reported here indicate that the lifetime reproductive success of control and deprived daughters does not differ by much, some evidence indicates that the same level of maternal food deprivation has large effects on the lifetime reproductive success of sons. For example, the brothers of the daughters of food-deprived mothers used in these experiments had smaller preputial glands and seminal vesicles than those of the brothers of daughters of control females (Meikle and Westberg, 2001). Sons of food-deprived mothers were about $50 \%$ less frequently dominant to sons of control mothers than vice-versa (Meikle and Westberg, 2001). In addition, Meikle et al. (1995) found that males born to mothers subjected to the same food deprivation protocol as that used in the present study were half again less attractive to oestrous females than were males born to control mothers. Hence, sons of control mothers are more likely to have greater survivorship and be able to establish and maintain a territory more readily than sons of food-deprived mothers. Sons born to control mothers are also likely to be chosen more frequently as mates than are sons of food-deprived mothers. The extent to which these factors that may influence reproduction differ in sons of control and food-deprived mothers indicates that the lifetime reproductive success of control sons may be several times higher than that of sons of food-deprived females (Meikle et al., 1995; Meikle and Westberg, 2001).

It is not surprising that maternal food deprivation during gestation has less effect on the reproductive success of daughters than that of sons. Poor maternal nutrition may disrupt testosterone-mediated organizational effects in males (Breedlove and Arnold, 1980; Lung and Cunha, 1980; Breedlove, 1992), resulting in adult mice devoid of the physical or behavioural characteristics that predispose them to be dominant during intrasexual agonistic encounters or attractive to potential mates. Female mice do not undergo such organizational effects and, therefore, may be relatively immune from the serious effects of mild food deprivation of their mothers during gestation. However, only a direct measure of reproduction of sons and daughters of control and food-deprived females in natural or semi-natural conditions will allow a rigorous comparison of the relative impact of maternal nutrition on the lifetime reproductive success of sons and daughters. 
The authors thank L. Hayes, P. Hogan, K. Lin, J. Mihalcin, C. Schandorsky, N. Solomon and M. Spritzer, and three anonymous reviewers for valuable comments and suggestions. This research was supported by the National Science Foundation (DEB9317874), Appalachian State University, Hood College, and by Miami University.

\section{References}

Alexander RD, Hoogland JL, Howard RD, Noonan KM and Sherman PW (1979) Sexual dimorphism and breeding systems in pinnipeds, ungulates, primates and humans. In Evolutionary Biology and Human Social Behavior pp 402-435 Eds NA Chagnon and W Irons. Duxbury Press, North Scituate, Massachusetts

Barker DJP (1999) In utero programming of cardiovascular disease Theriogenology 53 555-574

Breedlove SM (1992) Sexual differentiation of the brain and behavior. In Behavioral Endocrinology pp 39-70 Eds JB Becker, SM Breedlove and D Crews. MIT Press, Cambridge, Massachusetts

Breedlove SM and Arnold AP (1980) Hormone accumulation in a sexually dimorphic motor nucleus of the rat spinal cord Science 210 564-566

Bronson FH (1985) Mammalian reproduction: an ecological perspective Biology of Reproduction 32 1-26

Bronson FH (1989) Mammalian Reproductive Biology University of Chicago Press, Chicago

Clutton-Brock TH (1988) Reproductive success. In Reproductive Success pp 472-485 Ed. TH Clutton-Brock. University of Chicago Press, Chicago

Clutton-Brock TH and Parker GA (1992) Potential reproductive rates and the operation of sexual selection Quarterly Review of Biology 67 437-456

Clutton-Brock TH, Albon SD and Guinness FE (1988) Reproductive success in male and female red deer. In Reproductive Success pp 325-343 Ed. TH Clutton-Brock. University of Chicago Press, Chicago

DeFries JC and McLearn GE (1970) Social dominance and Darwinian fitness in the laboratory mouse The American Naturalist 104 408-411

Drickamer LC (1992) Oestrous female house mice discriminate dominant from subordinate males and sons of dominant from sons of subordinate males by odour cues Animal Behaviour 43 868-870

Drickamer LC and Meikle DB (1988) Food deprivation affects reproduction in adult female mice (Mus musculus) and the age of puberty for their female progeny Acta Biologica Hungarica 39 361-375

Drickamer LC, Gowaty PA and Holmes CM (2000) Free female mate choice in house mice affects reproductive success and offspring viability and performance Animal Behaviour 59 371-378

Fuchs S (1981) Consequences of premature weaning on the reproduction of mothers and offspring in laboratory mice Zeitschrift für Tierpsychologica 55 19-32

Hamilton GD and Bronson FH (1985) Food restriction and reproductive development in house mice Biology of Reproduction 32 773-778

Howell DC (1982) Statistical Methods for Psychology PWS Publishers, New York

Jakobson ME (1981) Physiological adaptability: the response of the house mouse to variations in the environment Symposium of the Zoological Society of London 47 301-335

König B (1994) Components of lifetime reproductive success in communally and solitary nursing house mice - a laboratory study Behavioral Ecology and Sociobiology 34 275-283

Krackow S (1993) The effect of weaning weight on offspring fitness in wild house mice (Mus musculus domesticus): a preliminary study Ethology $9576-82$

Krackow S (1997) Maternal investment, sex differential prospects, and the sex ratio in wild mice Behavioral Ecology and Sociobiology 41 435-443

Labov JB, Huck UW, Vaswani P and Lisk RD (1986) Sex ratio manipulation and decreased growth of male offspring of undernourished golden hamsters (Mesocricetus auratus). Behavioral Ecology and Sociobiology $18241-249$

Lung B and Cunha GR (1980) Development of seminal vesicles and coagulating glands in neonatal mice. I: The morphogenetic effects of various hormonal conditions Anatomical Record 199 73-88

McClure TJ (1966) Infertility in mice caused by fasting at about the time of mating Journal of Reproduction and Fertility 12 243-248

McClure PA (1981) Sex-biased litter reduction in food-restricted wood rats (Neotoma floridanus). Science 211 1058-1060

Meikle DB and Drickamer LC (1986) Food availability and secondary sex ration variation in wild and laboratory house mice (Mus musculus). Journal of Reproduction and Fertility 78 587-591

Meikle DB and Thornton MW (1995) Premating and gestational effects of maternal nutrition on secondary sex ratio in house mice Journal of Reproduction and Fertility 105 193-196

Meikle DB and Vessey SH (1988) Maternal dominance rank and lifetime survivorship of male and female rhesus monkeys Behavioral Ecology and Sociobiology 22 379-383

Meikle DB and Westberg MC (2001) Social dominance rank and accessory sex glands in wild adult male house mice born to food-deprived mothers Physiology and Behavior 72 359-364

Meikle DB, Kruper JH and Browning CR (1995) Adult male house mice born to undernourished mothers are attractive to oestrous females Animal Behaviour 50 753-758

Paul A and Kuester J (1990) Adaptive significance of sex ratio adjustment in semi-free-ranging Barbary macaques (Macaca sylvanus) at Salem Behavioral Ecology and Sociobiology 27 287-293

Paul A, Kuester J and Arnemann J (1992) Maternal rank affects reproductive success of male Barbary macaques (Macaca sylvanus): evidence from DNA fingerprinting Behavioral Ecology and Sociobiology 30 337-341

Rivers JPW and Crawford MA (1974) Maternal nutrition and sex ratio at birth Nature 252 297-298

Rugh R (1968) The Mouse: its Reproduction and Development Burgess Publishing Co., Minneapolis

Siegel S (1956) Nonparametric Statistics for the Behavioral Sciences McGraw Hill Book Co., New York

Singleton GR (1989) Population dynamics of an outbreak of house mice (Mus domesticus) in the mallee wheatlands of Australia - hypothesis of plague formation Journal of Zoology, London 219 495-515

Singleton GR and Redhead TD (1990) Structure and biology of house mouse populations that plague irregularly: an evolutionary perspective Biological Journal of the Linnaean Society 41 285-300

SPSS Inc. (1996) SPSS 7.5.2 for Windows (Standard Version) Chicago, Illinois

Triggs GS (1991) The population ecology of house mice (Mus domesticus) on the Isle of May, Scotland Journal of Zoology, London 225 449-468

Trivers RL and Willard D (1973) Natural selection of parental ability to vary the sex ratio of offspring Science 179 90-92

Ward RJ (1981) Diet and nutrition Symposium of the Zoogical Society of London 47 255-266

Wasser SK and Norton G (1993) Baboons adjust secondary sex ratio in response to predictors of sex-specific offspring survival Behavioral Ecology and Sociobiology 32 273-281

Wright SL, Crawford CB and Anderson JL (1988) Allocation of reproductive effort in Mus domesticus: responses of offspring sex ratio and quality to social density and food availability Behavioral Ecology and Sociobiology 23 357-365

Received 8 January 2001.

First decision 2 March 2001.

Accepted 16 May 2001. 